\title{
Efeitos dos óleos de amendoim, açafrão e oliva na composição corporal, metabolismo energético, perfil lipídico e ingestão alimentar de indivíduos eutróficos normolipidêmicos ${ }^{1}$
}

\author{
The effects of peanut, safflower, and olive oil on body \\ composition, energy metabolism, lipid profile \\ and food intake of eutrophic, normolipidemic subjects
}

Regiane Lopes SALES²

Neuza Maria Brunoro COSTA ${ }^{2}$

Josefina Bressan Resende MONTEIRO²

Maria do Carmo Gouveia PELUZIO²

Sandra Bragança COELHO²

Cristiane Gonçalves de OLIVEIRA ${ }^{2}$

Richard MATTES ${ }^{3}$

\section{R E S U M O}

\section{Objetivos}

O presente trabalho visou avaliar os efeitos do consumo dos óleos de amendoim, açafrão e oliva no perfil lipídico, composição corporal, metabolismo energético e ingestão alimentar em indivíduos eutróficos normolipidêmicos.

\section{Métodos}

Foram selecionados 32 indivíduos, divididos aleatoriamente em quatro grupos, tendo quatro mulheres e quatro homens em cada grupo, com idade entre 18 e 50 anos. Foi oferecido um milk shake aos voluntários no desjejum, veiculando uma quantidade equivalente a 30\% da sua energia basal na forma de óleo (amendoim, açafrão ou oliva), por um período de oito semanas, exceto para o grupo-controle, que não recebeu o shake.

\footnotetext{
1 Artigo elaborado a partir da dissertação de R.L. SALES, intitulada "Efeitos dos óleos de amendoim, açafrão e oliva na composição corporal, metabolismo energético, perfil lipídico e ingestão alimentar de indivíduos eutróficos normolipidêmicos". Programa de Pós-Graduação em Ciência da Nutrição, Universidade Federal de Viçosa, 2003. Financiado pelo Peanut Institute e CAPES

2 Universidade Federal de Viçosa, Departamento de Nutrição e Saúde. Av. P.H. Rolfs, s/n, Campus Universitário, 36570-000, Viçosa, MG, Brasil. Correspondência para/Correspondence to: N.M.B. COSTA. E-mail: <nmbc@ufv.br>.

3 Department of Foods and Nutrition, Purdue University, 700 W State Street, W. Lafayette, IN 47907-2059, USA.
} 
Foram realizadas avaliações dos valores de colesterol total e frações, triacilgliceróis, composição corporal, taxa de metabolismo basal, termogênese induzida pela dieta e ingestão alimentar dos indivíduos nas semanas basal, $4^{\mathrm{a}}$ e $8^{\mathrm{a}}$.

\section{Resultados}

Não foi observada diferença significante no perfil lipídico e na saciedade, no entanto, o grupo que recebeu óleo de açafrão apresentou valores de lipídios plasmáticos mais reduzidos. A ingestão dos óleos levou ao aumento do ganho de peso, sendo que o óleo de oliva proporcionou maior circunferência do quadril.

\section{Conclusão}

A adição dos óleos na dieta levou ao aumento da deposição de gordura corporal sem provocar alterações no perfil lipídico e ingestão dietética, ao contrário do relatado na literatura. O uso dos óleos em substituição a outros nutrientes energéticos da dieta, o maior número de voluntários e um período maior de intervenção devem ser investigados em estudos futuros.

Termos de indexação: apetite, azeite de oliva, composição corporal, metabolismo energético, óleo de açafrão, óleo de amendoim, perfil lipídico.

\section{A B S T R A C T}

\section{Objective}

The present study aimed at evaluating the effects of peanut, safflower and olive oils on the lipid profile, body composition and satiety of eutrophic, normolipidemic subjects.

\section{Methods}

Thirty-two 18 to 50 year-old subjects were recruited and randomly divided into four groups, each with 4 men and 4 women. One group received no treatment and the others received a milk shake for their breakfast, containing an amount of one of the oils (peanut, safflower or olive) equivalent to $30 \%$ of their basal energy metabolism, for a period of 8 weeks. The levels of total blood cholesterol and fractions, triacylglycerols, body weight, body composition, basal metabolic rate, dietary induced thermogenesis, satiety and food intake were evaluated on the basal, $4^{\text {th }}$ and $8^{\text {th }}$ weeks.

\section{Results}

No significant difference was observed in the lipid profile or satiety, but the safflower oil group showed lower levels of blood lipids. Oil intake, irrespective of its composition, led to an increase in body weight, and olive oil consumption increased the hip circumference.

\section{Conclusion}

Contrary to reports in the literature, the addition of oils to the diet increased body fat deposition, and had no effect on blood lipid profile or satiety. The use of oil to substitute other energetic nutrients of the diet should be investigated in future studies, with a larger number of volunteers and a longer period of intervention.

Indexing terms: appetite, olive oil, body composition, energy metabolism, safflower oil, peanul oil, lipid profile.

\section{N T R O D U Ç Ã O}

O papel dos constituintes da dieta na gênese e na prevenção de doenças e seus mecanismos de ação tem sido, há décadas, objeto de estudo. Entre os macronutrientes, os lipídios são os mais polêmicos na gênese de doenças, como alguns tipos de câncer, obesidade e a aterosclerose, que desencadeiam uma série de outras doenças cardiovasculares (DCV) $)^{1,2}$
Os efeitos dos lipídios, entretanto, são diferenciados conforme sua composição. A relação entre o consumo excessivo de ácidos graxos saturados (SFA) e o aumento do colesterol plasmático e a obesidade ${ }^{3}$ tem sido exaustivamente abordada na literatura. Por outro lado, o consumo de ácidos graxos poliinsaturados (PUFA) e de ácidos graxos monoinsaturados (MUFA) tem sido recomendado para melhorar o perfil lipídico 
em relação aos SFAs. Recentemente, alguns estudos $^{4-7}$ mostram que dietas ricas em PUFA não estão isentas de efeitos negativos, tendo sido demonstrado que esses ácidos graxos podem provocar um aumento da oxidação de LDL-colesterol, e/ou redução dos níveis da fração HDL-colesterol.

Há uma tendência em aumentar as recomendações de consumo de MUFA, que, segundo os autores supracitados, não afetam os níveis de $\mathrm{HDL}$, e atuam diminuindo os níveis sangüíneos tanto de LDL quanto de triacilgliceróis, sendo mais eficazes na prevenção das DCV ${ }^{8}$.

Mas vários aspectos metabólicos ainda precisam ser desvendados em relação ao tipo de ácido graxo e à quantidade que deve ser consumidos. Os pesquisadores se dividem em duas opiniões opostas quanto ao teor de lipídios na dieta: Kris-Etherton et al. ${ }^{1}$, Hu et al. ${ }^{4}$; Grundy ${ }^{9}$; O'Keefe et al. ${ }^{10}$; e Almario et al. ${ }^{11}$ defendem o consumo de dietas com teores normais a elevados de lipídios ricos em ácidos graxos insaturados. Segundo os mesmos, as dietas com baixos teores de lipídios, e, conseqüentemente, ricas em carboidratos, elevam significativamente os trigliacilgliceróis sangüíneos e reduzem os níveis de HDL. Por outro lado, Parks \& Hellerstein ${ }^{12}$ discordam, justificando que esses experimentos foram realizados em curto período e que o aumento dos triacilgliceróis plasmáticos é temporário, embora se mantenham um pouco mais alto quando comparados à dieta normolipídica. Segundo os autores, os benefícios de uma dieta com teores limitados de lipídios superpõem os daquela dieta cujos níveis de lipídios são elevados.

As diferenças metabólicas entre os ácidos graxos e suas respectivas quantidades não se limitam ao perfil lipídico. Segundo Summers et al. ${ }^{13}$; Lawton et al. ${ }^{14}$ e Garaulet et al. ${ }^{15}$, o tipo de ácido graxo ingerido pode influenciar no ganho de peso, composição corporal e saciedade, havendo diferença conforme o perfil dos ácidos graxos ingeridos.

Lawton et $a^{14}$ sugerem que o grau de saturação do ácido graxo influencia a saciedade, sendo os PUFAs os mais potentes em inibir a ingestão alimentar. No entanto, Bell \& Rolls ${ }^{16}$ encontraram que, independentemente do teor e do tipo de lipídio, a densidade energética do alimento ingerido é o fator determinante da quantidade a ser consumida, sendo que os de alta densidade têm pouco poder de saciação.

Contudo, os estudos ainda não são conclusivos e os trabalhos publicados, quanto aos efeitos dos MUFA e PUFA no desenvolvimento das DCV, são inconsistentes. Novos estudos são necessários para elucidar a relação dos lipídios com essas doenças. Assim, o objetivo do presente trabalho foi avaliar os efeitos do consumo dos óleos de amendoim, açafrão e oliva no perfil lipídico, ingestão alimentar, composição corporal e metabolismo energético de indivíduos eutróficos normolipidêmicos.

\section{MÉ T O D O S}

Utilizou-se o óleo de açafrão e de amendoim da marca Hollywood e o óleo de oliva italiano extra light da Pilippo Berio, doados pela Purdue University, como parte do projeto financiado pelo Peanut Institute.

Os óleos de amendoim, de açafrão e de oliva foram analisados por cromatografia gasosa, utilizando o modelo CG-17A Shimadzu/Class, com a coluna de sílica fundida SP-2560 (biscianopropil polysiloxane), de $100 \mathrm{~m}$ e $0,25 \mathrm{~mm}$ de diâmetro, com temperatura inicial de $140^{\circ} \mathrm{C}$ isotérmico por cinco minutos e posterior aquecimento de $4^{\circ} \mathrm{C}$ por minuto até $240^{\circ} \mathrm{C}$, permanecendo nessa temperatura por 30 minutos. A temperatura do vaporizador foi de $250^{\circ} \mathrm{C}$ e a do detector, $260^{\circ} \mathrm{C}$. O gás de arraste utilizado foi o hidrogênio em $20 \mathrm{~cm} / \mathrm{seg}$., a $175^{\circ} \mathrm{C}$. A razão da divisão da amostra no injetor foi de 1/50 e injetou-se $1 \mu \mathrm{L}$ da solução.

Os picos foram identificados por comparação dos tempos de retenção com padrões de metil ésteres conhecidos (SIGMA Chemical $\left.\mathrm{CO}^{\circledR}\right)$ e quantificados por áreas de integração automática. 
Foram recrutados 32 indivíduos saudáveis e eutróficos índice de massa corporal (IMC) entre 18 e $25 \mathrm{~kg} / \mathrm{m}^{2}$ de 18 a 50 anos de idade, sendo $50 \%$ do sexo masculino e $50 \%$ do feminino. Os voluntários apresentavam peso estável, com flutuação inferior a três quilos nos últimos seis meses. Foram excluídos do estudo indivíduos que faziam uso de medicamentos (exceto contraceptivos orais), fumantes, os que apresentaram padrão de atividade física elevado, hipertensos, dislipidêmicos, diabéticos e intolerantes à glicose (o ponto limítrofe de colesterol total de jejum inferior a $220 \mathrm{mg} / \mathrm{dL}$ de sangue), e proporção de lipídios ingerida na dieta inferior a 27\% do valor energético total (VET).

Os voluntários assinaram o termo de consentimento previamente aprovado pelo Comitê de Ética na Pesquisa com Seres Humanos da Universidade Federal de Viçosa.

Foram elaboradas onze preparações líquidas, constituídas de leite de vaca desnatado, açúcar, farinha (de composição semelhante à farinha láctea) e fruta. Todas as preparações elaboradas possuíam como única fonte lipídica o óleo em teste.

As preparações foram planejadas de modo a apresentarem teores de nutrientes semelhantes ao desjejum, sem, no entanto, fornecerem lipídio ou outro nutriente que apresentasse algum efeito sobre o perfil lipídico em humanos. Foram oferecidas aos voluntários em forma de milkshake imediatamente após o seu preparo. A composição química das preparações foi determinada a partir da análise dos ingredientes pelo programa DietPro, versão 4 . A essa composição acrescentou-se o óleo em quantidade individualmente determinada (30\% do gasto metabólico basal, mensurado por calorimetria indireta). Com essa adição, o valor energético total da preparação variou entre $690 \mathrm{kcal}$ e $760 \mathrm{kcal}$.

Os voluntários foram orientados a se encaminharem ao Laboratório de Estudos Experimentais de Alimentos do Departamento de Nutrição e Saúde, em jejum, onde ingeriram diariamente shakes de sabores variados, que veiculavam os óleos em teste (óleo de amendoim, açafrão e de oliva), em quantidades individualmente calculadas.

Os indivíduos foram pesados em balança eletrônica microdigital, com capacidade de $150 \mathrm{~kg}$ e precisão de $100 \mathrm{~g}$, utilizando-se o mínimo de roupa possível pela manhã, em jejum. A altura foi determinada utilizando-se antropômetro vertical milimetrado, com escala de $0,1 \mathrm{~cm}$.

Para avaliação do estado nutricional foi utilizado o IMC segundo Bray \& Gray ${ }^{17}$, relação cintura/quadril e o método da bioimpedância elétrica (BIA) (Biodynamics modelo 310) para a aferição do percentual de gordura corporal total, porcentagem de massa magra e porcentagem de água corporal.

A avaliação antropométrica e da composição corporal foi efetuada na semana basal e novamente nas semanas 4 e 8 .

Foram aferidos, como indicadores clínicos, a pressão arterial e os batimentos cardíacos com o auxílio do aparelho Automatic Blood Pressure Monitor with IntelliSense ${ }^{\mathrm{TM}}$ Modelo HEM-711AC nas semanas basal, 4 e 8.

A aferição do metabolismo energético foi realizada nos voluntários em jejum de 12 horas, com o mínimo de atividade física, pelo método de calorimetria indireta, utilizando o monitor metabólico Deltatrac ${ }^{\circledR}{ }^{\circledR}$ (Datex, Finlândia). Foram coletados dados de consumo de oxigênio, produção de dióxido de carbono do organismo e quociente respiratório (RQ).

A mensuração do metabolismo basal foi realizada durante um período de 30 minutos; em seguida, o voluntário recebeu uma carga do formulado com o óleo de adição correspondente a 30\% do seu gasto energético basal, previamente determinado. Os voluntários foram orientados a consumir a carga no tempo máximo de 30 minutos. A termogênese induzida pela dieta foi estimada por meio das leituras de 15 minutos a cada 30 minutos, após 1, 2, 3, 4 e 5 horas da ingestão da carga. Essas mensurações foram aferidas na semana basal e na semana 8 . 
Inicialmente realizou-se uma triagem por meio de punção digital, com aparelho AccuCheck $^{\circledR}$ InstantPlus ${ }^{\circledR}$ para avaliação dos níveis de colesterol, no recrutamento dos voluntários. Uma vez recrutados, os exames bioquímicos foram realizados em laboratório de análises clínicas, e permitiram a avaliação dos níveis de colesterol total e frações, triacilgliceróis e ácido úrico pelo método colorimétrico-enzimático ${ }^{18}$; glicose, creatinina (Cinético Jaffe - automatizado); uréia (Enzimático em U.V. Automatizado); além do hemograma completo (Scatter Laser) descrito por Henry ${ }^{19}$. Foram utilizados vaccuntainers com agulhas e tubos descartáveis na coleta dos $10 \mathrm{~mL}$ de sangue.

Os exames bioquímicos foram realizados nas semanas basal, 4 e 8 .

Foram levantados dados de consumo alimentar habitual pelo método de Registro Alimentar, aplicado em três tempos (duas vezes durante a semana e uma no final de semana, em dias não consecutivos), sendo avaliadas calorias totais, carboidratos, lipídios, proteínas, ácidos graxos, colesterol, fibras, vitaminas, minerais, álcool, arginina e lisina.

Para avaliação dos nutrientes, utilizou-se o programa de análises de dietas DietPro ${ }^{\circledR}$ (versão 4), desenvolvido pelo Departamento de Nutrição e Saúde da Universidade Federal de Viçosa ${ }^{20}$.

Foram recolhidos dados da ingestão dietética na semana basal e nas semanas 4 e 8 (três registros alimentares em cada semana). Os voluntários foram orientados a não alterarem os hábitos alimentares e atividade física durante o estudo.

Os parâmetros de ingestão alimentar foram registrados em uma escala de 9 pontos, contendo "nem um pouco de fome" e "extremamente faminto" nas extremidades, conhecida como escala bipolar ${ }^{21}$. As avaliações incluíram sensação de fome, de plenitude gástrica, desejo para se alimentar e o quanto o participante imaginava ser possível ingerir naquele momento (ingestão prospectiva).
Os indivíduos foram orientados a comparecer ao laboratório de Estudo Experimental de Alimentos em jejum de 12 horas entre 6h30min e $9 \mathrm{~h}$, onde, inicialmente, responderam ao questionário de avaliação do apetite, em jejum.

Logo em seguida, a formulação foi oferecida e eles tiveram 30 minutos para a sua ingestão. Ao final dos 30 minutos, os voluntários preencheram o questionário, voltando a preenche-lo 30 minutos depois. Durante esse tempo, os voluntários se abstiveram de quaisquer alimentos fazendo exceção à água. O questionário foi repetido ainda, de hora em hora, durante todo o dia, enquanto o voluntário permaneceu acordado.

Os indivíduos participantes do estudo foram avaliados em relação à atividade física com o uso do questionário de "atividade log", no qual foram registradas minuciosamente todas as atividades realizadas no período de 24 horas, perfazendo 1440 minutos. O questionário de atividade log foi aplicado nas semanas basal, 2, 4, 6 e 8 .

Utilizou-se o delineamento inteiramente casualizado para dividir os voluntários entre os quatro grupos experimentais, quais sejam: óleo de amendoim, açafrão, óleo de oliva e grupo- controle (que não recebeu shake). Cada um deles com oito voluntários, sendo $50 \%$ homens e $50 \%$ mulheres.

Os dados foram submetidos ao teste de Kolmogorov-Smirnov para avaliar a homogeneidade da distribuição. Em função do tamanho da amostra e pelo fato de a maioria das variáveis não apresentar distribuição normal, optou-se pela realização de testes não paramétricos.

Os efeitos do tratamento foram testados utilizando-se Análise de Variância por postos de Friedman para detectar modificações ao longo do tempo. Quando esse se apresentou significante, utilizou-se o procedimento de comparações múltiplas de Student-Newman-Keuls para complementá-lo. Para comparação entre os grupos experimentais, realizou-se o teste de análise de variância de Kruskal-Wallis e, quando 
a diferença era significativa, o teste StudentNewman-Keuls. Adotou-se o nível de significância de 0,05 .

Utilizou-se o software Sigma Stat 2.03 para análise estatística dos dados.

\section{RESULTADOS}

O óleo de amendoim apresentou maior percentual de ácidos graxos monoinsaturados, com o ácido oléico em maior concentração entre eles; para o óleo de açafrão a concentração foi maior em poliinsaturados e para o óleo de oliva, a concentração maior em monoinsaturados (Tabela 1).

Todos os voluntários preencheram satisfatoriamente os critérios adotados e concluíram o experimento com êxito, com o máximo de duas faltas ao longo do experimento.

Os grupos experimentais se mostraram homogêneos, sem diferença significante entre os grupos para os parâmetros antropométricos avaliados (Tabela 2). Os dados foram apresentados utilizando-se a mediana dos valores.
Os parâmetros antropométricos foram avaliados novamente na $4^{a}$ e $8^{a}$ semanas. Houve diferença significante entre os grupos ao longo do experimento somente para batimentos cardíacos na $8^{a}$ semana: o grupo do óleo de oliva (AZ) apresentou menor valor para esse parâmetro em relação aos demais grupos experimentais.

Os valores não tiveram significância a 5\% de probabilidade, pelo teste Student-Newman-Keuls.

Os parâmetros antropométricos foram avaliados separadamente para cada grupo experimental na semana basal (antes do tratamento), $4^{a}$ e $8^{a}$ semanas. Houve aumento significante de peso, percentual de gordura corporal e massa gorda nos grupos experimentais amendoim (AM), açafrão (AÇ) e oliva (AZ). Para o ganho de peso e IMC, o grupo AM apresentou diferença significante na metade final do experimento, e os grupos AÇ e AZ já apresentaram-na nas primeiras quatro semanas. O grupo AZ foi o único que apresentou um ganho significante na circunferência do quadril ao final do experimento.

Os parâmetros bioquímicos foram avaliados na semana basal, $4^{a}$ e $8^{a}$ (Tabela 3 ). Não houve

Tabela 1. Perfil de ácidos graxos dos óleos de amendoim, açafrão e oliva por análise cromatográfica.

\begin{tabular}{lccc}
\hline Ácido Graxo & Amendoim (g/100g de lipídio) & Açafrão $(\mathrm{g} / 100 \mathrm{~g}$ de lipídio) & Oliva (kg/100g de lipídio) \\
\hline Láurico (12:0) & - & 1,90 & - \\
Palmítico (16:0) & 12,00 & 16,28 & 14,19 \\
Esteárico (18:0) & 2,05 & - & 2,40 \\
Eicosanóico (20:0) & 1,30 & - & 0,44 \\
Behênico (22:0) & 2,80 & 18,18 & - \\
\hline Total de SFA & 18,15 & - & 17,03 \\
\hline Palmitoléico (16:1) & - & 16,31 & 0,79 \\
Oléico (18:1) & 46,58 & - & 71,44 \\
Erúcico (22:1) & - & 16,31 & - \\
\hline Total de MUFA & 46,58 & 65,50 & 72,23 \\
\hline Linoléico (18:2) & 32,00 & - & 10,03 \\
$\alpha$-Linolênico (18:3) & - & 65,50 & 0,42 \\
\hline Total de PUFA & 32,00 & $3,48: 0,87: 1$ & 10,45 \\
\hline P:M:S & $1,76: 2,5: 1$ & 3,48 & $0,61: 4,24: 1$ \\
P:S & 1,76 & 0,61 \\
\hline
\end{tabular}

SFA= ácidos graxos saturados; MUFA= ácidos graxos monoinsaturados; PUFA= ácidos graxos poliinsaturados; P:M:S= Razão poliinsaturado/monoinsaturado/saturado; P:S= Razão poliinsaturado/saturado. 
diferença significante entre os grupos experimentais nas semanas avaliadas.

Não houve diferença significante entre os tratamentos quanto aos macro e micronutrientes avaliados na semana basal, comprovando a homogeneidade do grupo. As diferenças estatisticamente significantes encontradas ao longo do experimento entre os tratamentos foram somente na fração lipídica da dieta. Observou-se um aumento no consumo de lipídio, que foi correspondente ao perfil de ácidos graxos do tipo de óleo adicionado (Figura 1).

Para os parâmetros de ingestão alimentar, sensação de fome, plenitude gástrica, desejo para

Tabela 2. Mediana dos parâmetros antropométricos avaliados entre os grupos nas semanas basal e $8^{\text {a }}$.

\begin{tabular}{|c|c|c|c|c|c|c|c|c|}
\hline Parâmetros & \multicolumn{2}{|c|}{ Amendoim (AM) } & \multicolumn{2}{|c|}{ Açafrão (AÇ) } & \multicolumn{2}{|c|}{ Oliva (AZ) } & \multicolumn{2}{|c|}{ Controle $^{\odot}$} \\
\hline Idade (anos) & \multicolumn{2}{|c|}{27,0} & \multicolumn{2}{|c|}{28,0} & \multicolumn{2}{|c|}{23,0} & \multicolumn{2}{|c|}{24,0} \\
\hline \multirow[t]{2}{*}{ Altura (m) } & \multicolumn{2}{|c|}{1,7} & \multicolumn{2}{|c|}{1,7} & \multicolumn{2}{|c|}{1,7} & \multicolumn{2}{|c|}{1,7} \\
\hline & Basal & $8^{\mathrm{a}}$ semana & Basal & $8^{\mathrm{a}}$ semana & Basal & $8^{a}$ semana & Basal & $8^{a}$ semana \\
\hline Peso $(\mathrm{kg})$ & 63,5 & 64,0 & 64,8 & 66,5 & 62,5 & 65,4 & 62,5 & 62,5 \\
\hline IMC & 22,0 & 22,7 & 23,5 & 23,9 & 21,1 & 22,0 & 22,6 & 22,8 \\
\hline Cintura $(\mathrm{cm})$ & 74,0 & 79,0 & 81,7 & 83,2 & 74,0 & 76,2 & 75,1 & 75,2 \\
\hline Quadril (cm) & 96,2 & 97,9 & 100,5 & 100,5 & 95,2 & 97,5 & 96,8 & 97,7 \\
\hline $\mathrm{RCQ}$ & 0,8 & 0,8 & 0,8 & 0,8 & 0,8 & 0,8 & 0,8 & 0,8 \\
\hline Massa Magra (kg) & 50,9 & 50,2 & 49,3 & 48,9 & 51,3 & 51,3 & 48,5 & 46,8 \\
\hline Massa Gorda (kg) & 15,4 & 15,8 & 15,1 & 16,4 & 11,7 & 13,3 & 14,0 & 15,2 \\
\hline Gordura Corporal (\%) & 24,4 & 24,8 & 21,6 & 25,7 & 18,1 & 20,7 & 22,5 & 24,9 \\
\hline TMB BIA (kcal) & 1550,0 & 1525,0 & 1501,0 & 1486,5 & 1558,5 & 1561,5 & 1477,5 & 1425,5 \\
\hline TMB DELTA (kcal) & 1675,0 & 1665,0 & 1475,0 & 1560,0 & 1705,0 & 1800,0 & 1630,0 & 1845,0 \\
\hline TID (kcal/min) & 5,4 & 7,0 & 5,1 & 6,0 & 5,5 & 4,5 & 5,8 & 5,4 \\
\hline P.S. (mmHg) & 122,5 & 115,0 & 123,0 & 120,0 & 110,0 & 110,0 & 115,0 & 100,0 \\
\hline P.D. $(\mathrm{mmHg})$ & 62,5 & 70,0 & 75,0 & 75,0 & 65,7 & 60,0 & 70,0 & 70,0 \\
\hline B.C. (batimento/min) & $59,0^{a}$ & $64,0^{a}$ & $61,0^{\mathrm{a}}$ & $69,5^{b}$ & $69,0^{a}$ & $65,4^{a}$ & $71,0^{\mathrm{a}}$ & $62,5^{a}$ \\
\hline
\end{tabular}

As medianas seguidas de letras distintas, na linha, diferem entre si pelo teste SNK, em nível de 5\% de probabilidade; quando não houve diferença significante a letra foi omitida. IMC= Índice de massa corporal; RCQ= Razão Cintura/ Quadril; TMB BIA= Taxa metabólica basal por meio da bioimpedância; TMB DELTA= taxa metabólica basal por meio do deltatrac; TID= Termogênese induzida pela dieta; P.S= Pressão Sistólica; P.D= Pressão diastólica; B.C= Batimento cardíaco.

Tabela 3. Mediana dos parâmetros bioquímicos entre os grupos, nas semanas Basal, $4^{\mathrm{a}}$ e $8^{\mathrm{a}}$.

\begin{tabular}{|c|c|c|c|c|c|c|c|c|c|c|c|c|}
\hline \multirow{2}{*}{ Parâmetro } & \multicolumn{3}{|c|}{ Amendoim } & \multicolumn{3}{|c|}{ Açafrão } & \multicolumn{3}{|c|}{ Oliva } & \multicolumn{3}{|c|}{ Controle } \\
\hline & Basal & $4^{a}$ & $8^{a}$ & Basal & $4^{a}$ & $8^{a}$ & Basal & $4^{a}$ & $8^{a}$ & Basal & $4^{a}$ & $8^{a}$ \\
\hline $\begin{array}{l}\text { Ácido Úrico } \\
(\mathrm{mg} / \mathrm{dL})\end{array}$ & 3,30 & 2,85 & 3,55 & 3,50 & 3,20 & 3,45 & 3,75 & 3,70 & 4,30 & 2,70 & 2,80 & 3,25 \\
\hline $\begin{array}{l}\text { Colesterol Total } \\
(\mathrm{mg} / \mathrm{dL})\end{array}$ & 149,50 & 148,50 & 157,50 & 154,50 & 153,00 & 150,50 & 138,00 & 141,00 & 151,50 & 162,50 & 157,50 & 165,50 \\
\hline $\mathrm{HDL}(\mathrm{mg} / \mathrm{dL})$ & 50,50 & 59,50 & 57,50 & 48,50 & 56,00 & 64,00 & 58,50 & 64,50 & 62,00 & 54,00 & 62,00 & 60,00 \\
\hline LDL (mg/dL) & 87,50 & 75,50 & 87,00 & 87,50 & 73,00 & 71,50 & 73,00 & 64,50 & 71,50 & 96,00 & 81,00 & 90,00 \\
\hline VLDL (mg/dL) & 15,50 & 14,50 & 17,50 & 13,00 & 13,00 & 14,00 & 11,50 & 9,50 & 13,00 & 12,50 & 12,00 & 12,50 \\
\hline $\begin{array}{l}\text { Creatinina } \\
(\mathrm{mg} / \mathrm{dL})\end{array}$ & 0,80 & 0,80 & 0,80 & 0,70 & 0,80 & 0,80 & 0,70 & 0,80 & 0,80 & 0,75 & 0,75 & 0,85 \\
\hline $\begin{array}{l}\text { Triacilgliceróis } \\
(\mathrm{mg} / \mathrm{dL})\end{array}$ & 71,50 & 70,00 & 85,50 & 62,50 & 62,00 & 67,50 & 54,00 & 44,50 & 63,50 & 59,40 & 57,80 & 61,50 \\
\hline Uréia (mg/dL) & 28,50 & 24,00 & 27,50 & 35,00 & 30,00 & 35,00 & 26,50 & 29,00 & 30,00 & 25,00 & 25,00 & 23,50 \\
\hline
\end{tabular}

Não houve diferença significante ao nível de $5 \%$ de probabilidade pelo teste SNK. 

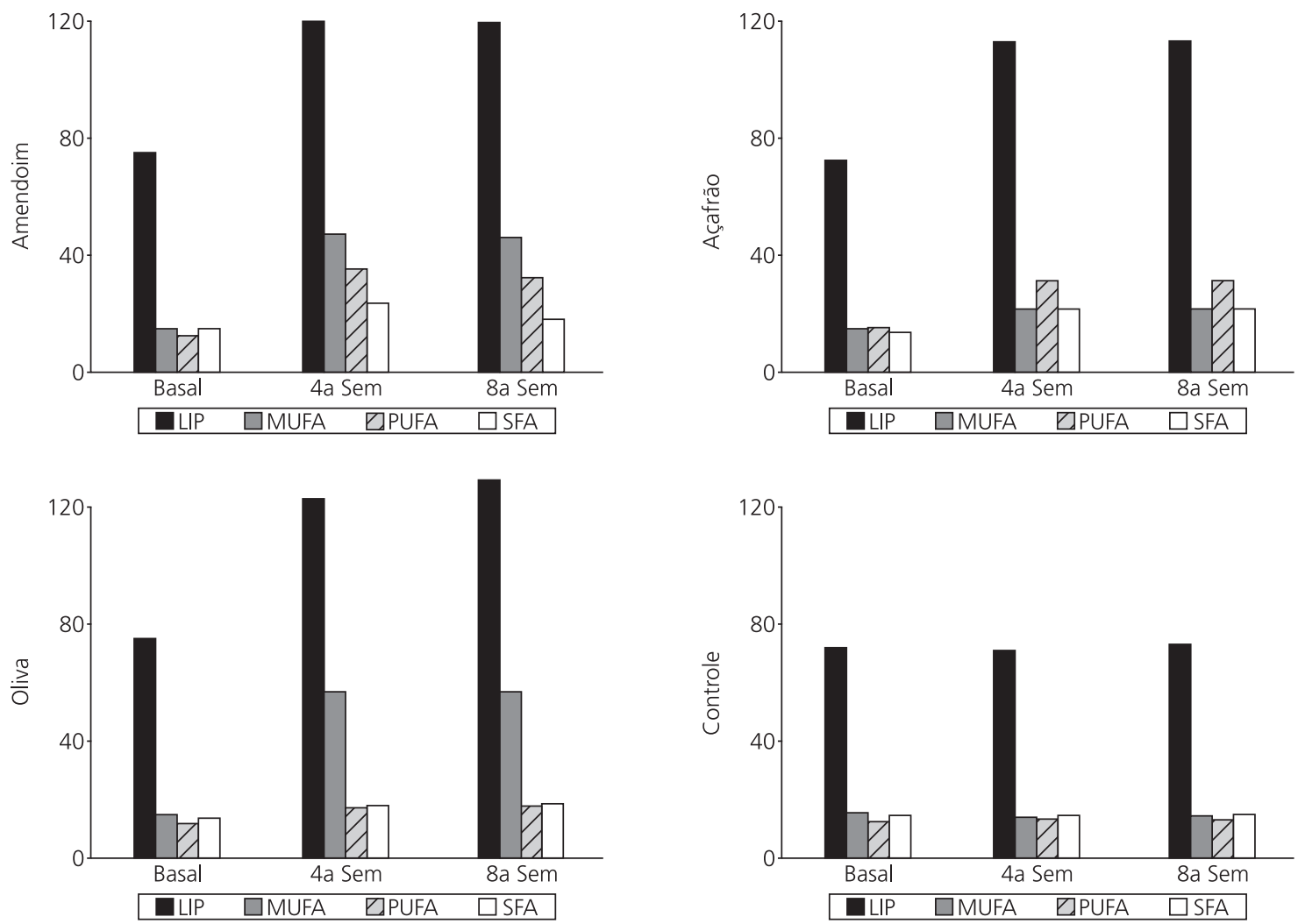

Figura 1. Alterações nos lipídios (g) ingeridos ao longo do experimento pelos grupos adicionados de óleo de amendoim, açafrão, oliva e grupo-controle.

se alimentar e ingestão prospectiva, não houve diferença significante para os tratamentos entre si, ou ao longo do tempo (dados não mostrados).

Os voluntários foram orientados, no início da pesquisa, a não alterarem o padrão de atividade física. Os dados obtidos de atividade log foram utilizados para fins de acompanhamento e não de determinação do gasto energético diário. Não foi observada alteração no padrão de atividade física entre os voluntários (dados não mostrados).

\section{I S C U S S Ã O}

Para os parâmetros antropométricos, houve variação somente no peso e percentual de gordura corporal, pois todos os tratamentos (exceto o controle) aumentaram o peso em valores estatisticamente significantes. Essa variação foi em média de dois quilos num período de apenas dois meses, o que representaria doze quilos em um período de doze meses, correspondente a $17 \%$ do peso corporal de um indivíduo de $70 \mathrm{~kg}$. Alguns estudos sobre o consumo de nozes e amendoim em humanos, fontes de PUFA e MUFA, respectivamente, verificaram que, embora esses alimentos sejam altamente energéticos, os indivíduos estudados não aumentaram o peso tanto quanto o consumo energético 1,4,11,22-24. Em outro estudo recente, Cintra ${ }^{25}$ também encontrou resultado semelhante em ratos, demonstrando, inclusive, que a composição do lipídio consumido influencia diretamente na deposição de ácidos graxos no tecido adiposo dos animais.

Para o grupo que recebeu óleo de amendoim, somente no segundo mês de adição é que esse ganho foi significante, embora o grupo tenha apresentado aumento no peso corporal semelhante aos demais. Para os demais tratamentos com 
os outros óleos, já na segunda avaliação antropométrica, os indivíduos apresentaram ganho significante no peso corporal.

Levine \& Silvis ${ }^{26}$ verificaram que $17,8 \%$ dos lipídios foram excretados pelas fezes quando os indivíduos consumiam o amendoim in natura, $7,0 \%$ quando consumiam manteiga de amendoim e 4,5\% com o óleo de amendoim. Isso pode explicar a diferença entre os efeitos antropométricos encontrados por aqueles pesquisadores e os do presente trabalho.

Considerando um quilo de tecido adiposo como $7700 \mathrm{kcal}^{5}$, e que a média de ingestão foi de $55 \mathrm{~g}$ de óleo adicionado (495kcal), num período de dois meses, esse indivíduo teria ingerido $29700 \mathrm{kcal}$ provenientes do óleo. Se todo lipídio ingerido fosse estocado, esse mesmo indivíduo teria, ao final do período experimental, acumulado $3,85 \mathrm{~kg}$ de tecido adiposo. Isso não ocorreu nos voluntários avaliados, visto que a mediana de ganho de tecido adiposo foi de 1,5kg, comparada com 1,15 do grupo-controle.

Summers et al. ${ }^{13}$ avaliaram a retirada de ácidos graxos da circulação sangüínea para o tecido adiposo após a ingestão de uma refeição contendo uma quantidade semelhante de ácido linoléico e oléico. De acordo com os autores, a deposição de ácido oléico no tecido adiposo é superior ao linoléico. As deposições no tecido adiposo e a composição do mesmo são complexas e não dependem simplesmente da taxa de lipídio ingerida, mas a maior deposição do ácido oléico pode ser uma das razões para explicar o ganho de peso maior nos indivíduos que receberam adição dos óleos de oliva e de amendoim.

Os voluntários do grupo AZ apresentaram deposição regionalizada significante na circunferência do quadril. Esse efeito não foi observado nos demais grupos. Esses dados estão de acordo com os de Garaulet et al. ${ }^{15}$. Segundo os autores, os PUFA $\omega 6$ tendem a se depositar mais na região da cintura, enquanto que os MUFA $\omega 3$ a se depositarem, preferencialmente, na região do quadril. De acordo com o perfil de ácidos graxos dos óleos utilizados e os resultados de ganho de cintura e quadril dos indivíduos, o óleo de açafrão (rico em PUFA) não modificou a circunferência do quadril, havendo um pequeno ganho na circunferência da cintura. Para o óleo de amendoim (fonte de PUFA e MUFA), esse ganho foi equivalente para ambas as circunferências. Mas para o óleo de oliva, a maior fonte de MUFA estudada, especialmente rica em oléico ( $72 \%$ da composição total de ácidos graxos), houve esse ganho na circunferência do quadril e conseqüente redução da RCQ.

O grupo que recebeu óleo de oliva também apresentou uma redução dos batimentos cardíacos, que não foi correspondente à redução na pressão sistólica ou diastólica, mas tanto o grupo adicionado com óleo de amendoim quanto o grupo adicionado de óleo de oliva mostraram uma tendência a reduzi-las. Apesar de não apresentar significância estatística, essa tendência tem uma importância biológica, principalmente para indivíduos acometidos por doenças como hipertensão arterial ou diabetes. Rasmussen et al. ${ }^{27}$, em um estudo comparativo de uma dieta rica em monoinsaturados com outra hipolipídica, rica em carboidratos em indivíduos diabéticos, relataram uma redução na pressão sangüínea para o grupo que consumia dieta rica em MUFA.

Para os parâmetros bioquímicos, nenhuma diferença significante foi encontrada entre os grupos experimentais ao longo do estudo. O período de intervenção de oito semanas pode ter sido insuficiente para detectar alguma diferença. Aliado a isso, segundo Kris-Etherton et al. ', indivíduos com valores baixos para os lipídios plasmáticos têm uma resposta lipidêmica menor em relação àqueles com valores plasmáticos mais elevados. Isso também pode ter contribuído para esses resultados, já que o grupo foi composto por indivíduos jovens, com valores iniciais de colesterol plasmático inferiores a $220 \mathrm{mg} / \mathrm{dL}$.

O melhor perfil lipídico observado foi alcançado pelo grupo que recebeu óleo de açafrão, no qual foram observados redução do colesterol total, LDL e aumento da HDL em níveis superiores aos demais tratamentos, no entanto, sem diferença estatística. 
Segundo Yu-Poth et al. ${ }^{7}$, um efeito indesejável que o alto consumo de PUFA promove é a maior suscetibilidade da LDL sofrer peroxidação lipídica; esse dado não foi estudado no presente trabalho, no entanto, Miller et al. ${ }^{28}$ mostraram que o fornecimento de $\alpha$-tocoferol reduz essa peroxidação. Segundo informação do fabricante, o óleo de açafrão utilizado possui 4,5 UI de tocoferol por $\mathrm{mL}$ em sua composição.

Outro efeito desfavorável ao PUFA $\omega 6$, citado por Schmidt ${ }^{5}$, é que ele leva à produção de leucotrienos e prostaglandinas da série 2 , que são substâncias pró-inflamatórias como tromboxanos da série 2, que estimulam a agregação plaquetária. A alteração nos níveis de $\omega 6$ e $\omega 3$ na dieta pode levar a profundas mudanças nos processos biológicos envolvendo eicosanóides, como inflamação e coagulação sangüínea. Isso deve ser considerado, no entanto, a presente pesquisa não contemplou essa análise.

Os indivíduos que receberam óleos fonte de MUFA ( $A M$ e AZ) não apresentaram alterações significantes nos níveis de HDL, LDL e TAG, embora esses resultados tenham sido diferentes daqueles apresentados pelos trabalhos referenciados na revisão de literatura ${ }^{1,4,7,22,23,29}$. Em todos eles houve redução do lipídio dietético total, principalmente o SFA substituido pelo MUFA. Nesse experimento, não houve redução da fração lipídica dietética dos indivíduos. Apesar de não ser estatisticamente significante, houve aumento na fração SFA ao longo do experimento, como pode ser visualizado na (Figura 1).

A ingestão dietética foi bastante homogênea entre os grupos e, ao longo do experimento, apenas o perfil de ácidos graxos ingeridos e os lipídios totais apresentaram diferenças estatísticas correspondentes ao tipo de lipídio adicionado no período.

Como todos os outros nutrientes, a composição química foi fornecida por tabelas do banco de dados do programa Diet Pro 4, complementadas pela tabela de composição de alimentos de Philippi $^{30}$, para PUFA, MUFA e SFA, exceto o perfil ácidos graxos dos óleos utilizados. Cabe aqui ressaltar que nem todos os alimentos têm sua composição completa nas tabelas de composição disponíveis. Nelas, o tipo de ácido graxo geralmente é omitido. As indústrias que comercializam alimentos como biscoitos, bolos e chocolates fornecem valores nutricionais incompletos dos produtos, apontando somente os teores de ácidos graxos saturados totais, sem menção dos MUFA, PUFA e tipos de ácidos graxos constituintes. E tais alimentos são consumidos freqüentemente.

Com a finalidade de reduzir a diferença de ácidos graxos consumidos e os quantificados pelas tabelas, utilizou-se preferencialmente a tabela americana do United States Department of Agriculture (USDA) do banco de dados do Diet Pro, uma vez que somente essa discrimina os ácidos graxos dos alimentos.

Não houve aumento do VCT estatisticamente significante, mas quando avaliado por refeição, o consumo energético foi estatisticamente maior no desjejum dos grupos experimentais em relação ao controle.

Embora os shakes oferecidos tivessem cerca de $350 \mathrm{kcal}$ a mais quando comparados ao desjejum anterior ao experimento, e ao consumido pelo grupo-controle, isso não modificou a saciação e saciedade dos voluntários para nenhum dos óleos avaliados. O consumo energético, embora maior no desjejum, não modificou o fracionamento da dieta, e, no decorrer do dia, não houve diferença energética ou da distribuição de macronutrientes.

No desjejum, os indivíduos receberam uma carga composta por cerca de $65 \%$ de lipídio, comparados com cerca de $30 \%$ de lipídio ingerido anteriormente pelo grupo-controle. Esses resultados diferem dos encontrados por Lawton et al. ${ }^{14}$, que os testarem a saciedade em indivíduos, oferecendo uma dieta contendo cerca de $44 \%$ a $45 \%$ de lipídio (semelhante à do presente trabalho), rica nos ácidos graxos oléico ou linoléico, sugeriram que o grau de saturação influencia na saciedade, sendo o linoléico mais 
saciável em relação ao oléico. Segundo os autores, os PUFA são preferencialmente metabolizados (pela $\beta$-oxidação) em relação aos MUFA, sendo estocados em menor intensidade.

Ainda segundo Lawton et al. ${ }^{14}$, indivíduos recebendo fonte de ácido linoléico apresentaram ganho de peso inferior àqueles recebendo fonte de ácido oléico. No entanto, os autores utilizaram o chocolate para veicular o óleo, oferecido no almoço. Diferente desse experimento, no qual foi usada uma preparação líquida no desjejum, a diferença de ganho de peso não foi significante. Segundo DiMetlio \& Mattes ${ }^{31}$, bebidas apresentam baixo poder de saciedade, e os indivíduos não diminuem o consumo energético posterior ao consumo das mesmas. O fato de ter oferecido toda a carga de lipídios na forma líquida pode ter contribuído para o baixo poder de saciedade observado.

Lawton et al. ${ }^{14}$ citam ainda que a razão P:S influencia nos níveis de metabolização de macronutrientes no corpo, sendo que os SFA, em relação aos PUFA, levam mais tempo para entrar na $\beta$-oxidação, favorecendo a sua deposição no tecido adiposo. Assim, quanto maior essa razão, menor a deposição de lipídios. Por outro lado, Alfenas \& Mattes ${ }^{32}$, estudando o efeito do óleo de canola, amendoim (MUFAs) e manteiga (SFA) na saciedade, não encontram diferença significante.

Bell \& Rolls ${ }^{16}$ identificaram que a porcentagem de lipídio na dieta não é tão importante quanto a densidade energética e a palatabilidade do alimento, que, segundo os autores, são os grandes determinantes da ingestão de energia, independentemente dos macronutrientes constituintes, não sendo os alimentos de alta densidade energética tão eficazes em suprimir a fome quanto aqueles de baixa densidade. Os lipídios, por conterem alta densidade energética, seriam fracos opressores da sensação de fome, ou seja, possuem baixa saciedade.

Os estudos sobre lipídio e saciedade ainda não são conclusivos, fazendo-se necessária, portanto, a realização de mais pesquisas sobre o tema. Diferentemente da maioria das publicações envolvendo MUFA e PUFA, no presente trabalho não foi verificada alteração no consumo dos voluntários, que foram instruídos a não modificar o padrão de atividade física e nenhuma informação foi fornecida quanto ao teor energético ou composição das preparações, não influenciando, dessa forma, o consumo posterior.

O grupo de indivíduos estudado, constituído de oito indivíduos para cada tratamento, quatro homens e quatro mulheres, provavelmente não foi suficiente para possibilitar a verificação de diferenças significantes para os parâmetros avaliados para cada sexo separadamente.

\section{CONCLUSÃO}

Apesar de mostrarem tendências diferentes, os óleos de amendoim, açafrão e de oliva quando adicionados à dieta, na forma de shakes, não provocaram diferença significante nos níveis plasmáticos de lipídios dos indivíduos.

Houve aumento de peso dos indivíduos que consumiram os lipídios, sendo que o óleo de oliva tendeu a se depositar em maior quantidade em relação aos outros tratamentos e o óleo de açafrão surtiu menor ganho de peso.

Não houve diferença entre os óleos para os parâmetros de avaliação da ingestão alimentar. Embora não significante, houve apenas um aumento da ingestão energética, concentrada no desjejum dos indivíduos, independentemente do tratamento.

A modulação do perfil lipídico, a saciedade e a composição corporal por meio da ingestão dietética ainda requer em mais pesquisas voltadas não somente para o grau de saturação dos óleos, mas pelo comprimento da cadeia e isomerização e efeito particular de cada ácido graxo.

\section{A GRADECIMENTOS}

A professora Sylvia Franceschini pelas orientações nas análises estatísticas. Ao Peanut 
Institute e Purdue University pela doação dos óleos e financiamento da pesquisa. À CAPES pela concessão da bolsa de mestrado. E aos voluntários pela participação.

\section{R E F E R Ê N CIAS}

1. Kris-Etherton PM, Pearson TA, Wan Y, Hargrove $R L$, Moriarty $K$, Fishell $V$, et al. High-monounsaturated fatty acid diets lower both plasma cholesterol and triacylglycerol concentrations. Am. J Clin Nutr. 1999; 70(6): 1009-15.

2. Kubow S. The influence of positional distribution of fatty acids in native, interesterified and structure-specific lipids on lipoprotein metabolism and atherogenesis. J Nutr Biochem. 1996; 7(10): 530-41.

3. Prentice AM, Black AE, Murgatroyd PR, Goldberg GR, Coward WA. Metabolism or appetite: questions of energy balance with particular reference to obesity. J Human Nutr Diet. 1989; 2:95-104.

4. Hu FB, Stampfer MJ, Manson JE, Rimm EB, Colditz GA, Rosner BA, et al. Frequent nut consumption and risk of coronary heart disease in women: prospective cohort study. BMJ. 1998; 317(7169): 1341-5.

5. Schimidt MA. Gorduras inteligentes. Como as gorduras e os óleos afetam as inteligências mental, física e emocional. São Paulo: Roca; 2000.

6. Eritsland J. Safety considerations of polyunsaturated fatty acids. Am J Clin Nutr. 2000; 71(1):S197-201.

7. Yu-Poth S, Etherton TD, Reddy CC, Pearsno TA, Reed R, Zhao G, et al. Lowering dietary saturated fat and total fat reduces the oxidative susceptibility of LDL in healthy men and women. J Nutr. 2000; 130(9):2228-37.

8. Pelkman CL, Fishell VK, Maddox DH, Pearson TA, Manger DT, Kris-Etherton PM. Effects of moderate-fat (from monounsaturated fat) and low-fat weight-loss diets on the serum lipid profile in overweight and obese man and women. Am J Clin Nutr. 2004; 79(2):204-12.

9. Grundy SM. Comparison of monounsaturated fatty acids and carbohydrates for lowering plasma cholesterol. N Engl J Med. 1986; 314(12):745-8.

10. O'Keefe Jr JH, Nuyen T, Nelson J, O'Keee JO, Miles JM. Potential beneficial effects of monounsaturated and polyunsaturated fats in elderly patients with or at risk of coronary artery disease. Card Elderly. 1995; 3:5-10.
11. Almario RU, Vonghavaravat $V$, Wong R, KasimKarakas SE. Effects of walnut consumption on plasma fatty acids and lipoprotein in combined hyperlipidemia. Am J Clin Nutr. 2001; 74(1):72-9.

12. Parks EJ, Hellrstein MK. Carbohydrate-induced hypertriacylglycerolemia: historical perspective and review of biological mechanisms. Am J Clin Nutr. 2000; 71(2):412-33.

13. Summers LKM, Barnes SC, Fielding BA, Beysen C, Ilic V, Humphreys SM, et al. Uptake of individual fatty acids into adipose tissue in relation to their presence in the diet. Am J Clin Nutr. 2000; 71(6):1470-7.

14. Lawton CL, Delargy HJ, Brockman J, Simith RC, Blundell JE. The degree of saturation of fatty acids influences post-ingestive satiety. Br J Nutr. 2000; 83(5):473-82.

15. Garaulet M, Pérez-Llamas F, Pérez-Ayala M, Martínez P, Medina FS, Tebar FJ, et al. Site-specific differences in the fatty acid composition of abdominal adipose tissue in a obese population from a Mediterranean area: relation with dietary fatty acids, plasma lipid profile, serum insulin, and central obesity. Am J Clin Nutr. 2001; 74(5):585-91.

16. Bell EA, Rolls BJ. Energy density of foods affects energy intake across multiple levels of fat content in lean and obese women. Am J Clin Nutr. 2001; 73(6):1010-8.

17. Bray GA, Popkin BM. Dietary fat intake does affect obesity! Am J Clin Nutr. 1998; 68(6):1157-73.

18. National Cholesterol Education Program Executive summary of the Third Report of the National Cholesterol Program Expert panel on detection, evaluation and treatment of high blood cholesterol in adults (Adult Treatment Panel III). JAMA. 2001; 285(19):2486-97.

19. Henry JB. Diagnósticos clínicos e tratamento por métodos laboratoriais. 18.ed. Rio de Janeiro: Mamele; 1995. p.1678.

20. Esteves EA, Siqueira AD, Monteiro JBR, Ludwig A. Windiet. Sistema de apoio à decisão para avaliação do estado nutricional e prescrição de dietas. Arch Latinoam Nutr. 1998; 48:236-41.

21. Merrill EP, Kramer FM, Cardello A, Schutz H. A comparison of satiety measures. Appetite. 2002; 39(2):181-3.

22. Fraser GE, Sabaté J, Beeson WL, Strahan TM. A possible protective effect of nut consumption on risk o coronary heart disease: The Adventist Health Study. Arch Int Med. 1992; 152(7):1416-24.

23. O’Byrne DJ, Knauft DA, Shireman RB. Low fatmonounsaturated rich diets containing high-oleic peanuts improve serum lipoprotein profiles. Lipids. 1997; 32(7):687-95. 
24. Zambón D, Sabaté J, Muñoz S, Campero B, Casals E, Merlos M, et al. Substituting walnuts for monounsaturated fat improves the serum lipid profile of hypercholesterolemic men and women: a randomized crossover trial. Ann Intern Med. 2000; 132(7):538-46.

25. Cintra DEC. Perfil lipídico de ratos submetidos à dieta hipercolesterolemiante à base de linhaça (Linum usitatissimum), amendoim (Arachis hypogaea), truta (Oncorhynchus mykiss) ou pele de frango [dissertação]. Viçosa (MG): Universidade Federal de Viçosa; 2003.

26. Levine AS, Silvis AE. Absorption of whole peanuts, peanut oil, and peanut butter. N Engl J Med. 1987; 16:917-8.

27. Rasmussen OW, Thomsen C, Hansen KW, Vesterlund M, Winther E, Hermansen K. Effects on blood pressure, glucose, and lipid levels of a highmonounsaturated fat diet compared with a highcarbohydrate diet in NIDDM subjects. Diabetes Care. 1993; 16(12):1565-71.
28. Miller ER 3rd, Apple LJ, Risby TH. Effects of dietary patterns on measures of lipid peroxidation: Results from a randomized clinical trial. Circulation. 1998; 98(22):2390-5.

29. McNara DJ. Dietary fatty acids, lipoproteins, and cardiovascular disease. Adv Food Nutr Res. 1992; 36:253-351.

30. Phillippi ST. Tabela de composição de alimentos: suporte para decisão nutricional. Brasília: ANVISA; 2001. 133p.

31. DiMeglio DP, Mattes RD. Liquid versus solid carbohydrate: effects on food intake and body weight. Int J Obes. 2000; 24(6):794-800.

32. Alfenas RCG, Mattes RD. Effect of fat sources on satiety. Obes Res. 2003; 11(2):183-7.

Recebido para publicação em 14 de junho de 2004 e aceito em 18 de novembro de 2004. 